Iranian Journal of Pathology | ISSN: 2345-3656

\title{
Comparing the Efficacy of Virtual and Conventional Methods in Teaching Practical Pathology to Medical Students
}

\author{
Alireza Abdollahi ${ }^{1,2 *}$, Samaneh Salarvand ${ }^{1}$, Hiva Saffar ${ }^{3}$ \\ 1. Dept. of Pathology, School of Medicine, Imam Hospital Complex, Tehran University of Medi- \\ cal Sciences, Tehran, Iran \\ 2. Associate Editor, Iranian Journal of Pathology, Tehran, Iran \\ 3. Dept. of Pathology, School of Medicine, Shariati Hospital, Tehran University of Medical Sci- \\ ences, Tehran, Iran
}

\begin{tabular}{|c|c|}
\hline Article Info & \\
\hline \multirow{3}{*}{\multicolumn{2}{|c|}{$\begin{array}{c}\text { Received } 19 \text { Dec 2017; } \\
\text { Accepted } 05 \text { April 2018; } \\
\text { Published Online 17 July 2018; }\end{array}$}} \\
\hline & \\
\hline & \\
\hline Corresponding information: & $\begin{array}{l}\text { Alireza Abdollahi, Professor of Pathology, Dept. of Pathology, School of Medicine, Imam Hospi- } \\
\text { tal Complex, Tehran University of Medical sciences, Tehran, Iran. E-mail: dr_p_abdollahi@yahoo.com }\end{array}$ \\
\hline
\end{tabular}

Copyright (C) 2018, IRANIAN JOURNAL OF PATHOLOGY. This is an open-access article distributed under the terms of the Creative Commons Attribution-noncommercial 4.0 International License which permits copy and redistribute the material just in noncommercial usages, provided the original work is properly cited.

Old educational methods are gradually replaced by multimedia since 1990s (1). Today, most educational systems are applying advanced technology to meet the demands of students and academic faculties. Several studies show that a combination of traditional and electronic teaching methods can improve learning outcomes (2). The inclination to apply electronic learning tools in medical schools is also increasing (3).

The pathology course to study diseases is one of the most significant subjects taught at medical universities (2). It is extremely important for medical students to learn pathology concepts to conduct assessments, making diagnoses, and providing therapy (4). Besides theoretical education, medical students should pass practical courses at laboratories. Different devices and facilities such as microscopes and microscopic slides, lecturers, and scheduling are required to work at laboratories $(1,2)$. Recently, modern information technologies, as an integral part of medical technology, are implemented by health professionals in a bid to provide faster, more reliable, and comprehensive data collection $(5,6)$. Medical electronic learning uses information technology for educational activities. Electronic learning introduces a powerful teaching device for deeper and more efficient learning as well as distance learning (7). Other studies conducted on this subject highlighted the strengthening of learning, the expansion of knowledge, and growing interest in students due to the use of computer-assisted educational objects at pathology laboratories (4).

The current cross sectional, descriptive study was conducted by the Pathology Department of Tehran University of Medical Sciences (Tehran, Iran) in the first semester of 2016.The topic and the slides taught for practical pathology were selected earlier based on the curriculum of medical sciences by the Education Council of the Department and approved. High-quality digital images of the slides and the envisaged curriculum were presented in the form of an e-file (a total of 250 slides were provided). Then after necessary coordination, the digital images and curricula were posted on the learning management system (LMS) of the Virtual Department.

In the first session, the reason, statement of problem, and objectives were explained to the students. Then, the medical students were asked to register for participation in conventional or virtual groups. The first group underwent a traditional education (theoretical courses followed by practical microscopy laboratory with professor presentation) and the other group was exposed to distance learning (after signing informed consent). The members of virtual group were given the website address of the virtual school after a brief- 
ing. The students were required to click into the website where the materials were uploaded to download files one by one. Two sessions were also held in the middle and end of the semester to answer questions raised by the students.

At the end of the semester, both groups were evaluated scientifically according to a predefined plan; the evaluation at the end of semester was conducted routinely. All students took the exam and were led in 20-member groups to microscope halls. Each student was asked to describe four or five slides plus three theoretical questions. Finally, the results of the evaluation of both groups were compared and analyzed. Furthermore, their polling papers were examined.

Statistical analysis was conducted with SPSS version 18 . Mean \pm standard deviation (SD) was considered for the analysis of quantitative variables. Independent $t$ test was applied to compare variables and outcomes of the two groups. The significance level was set to 0.05 .

Participants signed the consents and were assured of the confidentiality of personal information. No extra cost was levied on subjects entitled to quit whenever they wished. Ethics approval for the study protocol was obtained from the Institutional Review Board of Tehran University of Medical Sciences in compliance with the Helsinki declaration.

The current study enrolled 126 third-year undergraduate medical students from Tehran University of Medical Sciences. Of the participants, 109 students (52 male and 57 female) attended conventional training course and sixteen (14 male and 2 female) volunteer students agreed to work in virtual groups. The mean score of final exam for all students in practical pathology course was 16.11 (maximum score: 20, minimum score: 3 ). The mean score in the conventional and virtual groups was $16.20 \pm 3.25$ and $16.59 \pm 3.60$, respectively. Independent $t$ test showed that the mean final pathology exam grade in the experimental group was higher than that of their counterparts in the control group; however, the difference between the two groups was not statistically significant $(P=0.658$ ).

The results of the current study showed that at our academic center, virtual education was as effective as conventional method in teaching and academic guidance. Other studies also showed that implementing electronic learning in their teaching centers or its combination with traditional teaching methods was also useful $(8,9,10)$. In line with the current study findings, Hosseini et al., showed that the average scores of dentistry students using the software (CD$\mathrm{ROM}$ ) as an educational package in practical pathology were higher than those of the traditional group; however, the difference between groups was not statistically significant $(16.23 \pm 3.36$ vs. $15.22 \pm 3.52$, $P=0.19$ ) (1). On the other hand, in consistence with the current study results, Ariana et al., showed that the mean final pathology exam grade in the experimental group with electronic self-directed learning material was significantly higher than that of their counterparts in the control group with traditional learning method $(96.13 \% \pm 5.73 \%$ vs. $85.43 \% \pm 10.23 \%$; $\mathrm{P} \leq 0.05)$ (2). Moazami et al., also demonstrated a higher mean knowledge score and more effective learning in virtual learning method than in traditional and lecturebased training method (11).

Several studies highlighted the effectiveness and values of virtual teaching system; Sinn et al., confirmed that implementing virtual microscopy in pathology teaching facilitates the students> access to histology slides beyond the lab made it an ideal tool for teaching and postgraduate training in pathology (12). Ruiz et al., (3) also believed that electronic learning technology can provide some valuable opportunities for medical students. Al-Neklawy et al., believed that the traditional didactic lecture cannot provide adequate time for deeper learning activities. The current study did not evaluate the students' satisfaction, but the students indicated the satisfaction of most students by implementing virtual learning methods in embryology course (with regard to the efficacy of the instructional methods and the degree of clarity of the course material) (13). Lichnovská et al., pointed to a better resolution and image quality of virtual histology slides, which would dispense with the need to keep and store hundreds of slides, prevent loss or breakage of slides, and provide a user-friendly and 
more efficient educational tool for the students (14). Furthermore, average and below-average students can use the electronic material several times until they reach complete understanding and satisfaction (15). Peroz et al., showed some other findings; although conventional method had more educational and enjoyment values, more students preferred to participate in computer assisted learning classes. Moreover, the authors indicated a better knowledge in the short term among students in the class, but in the long term no difference was observed in the knowledge retention of computer assisted learning and the lecture groups (16).

Several investigations indicated some advantages of electronic learning in higher education; in other words, some disadvantages were also reported. Only few students and faculty members had insufficient experience or were afraid of web-based learning and technology (17). In addition, no face-to-face interaction, communication, and collaboration occurred between the students and the staff. The students> perception of the educational environment is not improved by virtual learning method (15). Finally in such learning methods, clinical and practical skills, some abilities related to asking questions, problem solving, providing orientation, getting feedback, and encouraging reflections are not practiced.

Based on recent policies of Tehran Medical University, incorporation of electronic learning into all edur cational curriculums by at least $15 \%$ of educational topics is strongly suggested. The learning management system (LMS) of the Virtual Department of Tehran University of Medical Sciences also provides a comprehensive and powerful system to manage

- the possibility for faculty members, residents, and $\mathrm{PhD}$ students and everyone else throughout the country to have access to the system

- the possibility of presenting fully virtual programs (interaction with audience through education) while individual learning routes being forecasted

- the possibility of staging low-residency or virtual workshops and short-term courses under supervision of workshop teachers

- the possibility of uploading and preparing programs and workshops by teachers about the topic, objectives, introduction, audience, scientific content, assignments, tests, and discussion room

- the possibility of copying and editing previous programs and workshops for new presentation

drawing up study report for the audience, including half-finished programs and workshops, completed ones, and the issued certificates

In accordance with these policies, strategies, accessibility and support, faculty members of our department assume that in the pathology course, the use of highquality virtual slides in microscopic examination provides an efficient, new, comfortable, meaningful, and interesting field. Students benefit from virtual class regardless of the availability of lab physical atmosphere and limited facilities, the number of students and faculties as well as time and date.

In conclusion, the current study indicated that to teach practical pathology, virtual education may be as effective as conventional methods; however, further studies are needed to confirm the obtained results.

\section{Conflicts of interest}

The author declared no conflict of interest.

\section{References}

1. Hosseini SV, Aghbali A, Emamverdizadeh P, Hasani A, Razbani M. Using E-learning in Teaching the Quality of the Practical Oral Pathology on Dentistry Students. Res Dev Med Educ. 2014;3(1):61-5. http://dx.doi.org/10.5681/ $\underline{\text { rdme.2014.013 }}$

2. Ariana A, Amin M, Pakneshan S, Dolan-Evans E, Lam A. Integration of Traditional and E-Learning Methods to Improve Learning Outcomes for Dental Students in Histopathology. J Dent Educ. 2016;80(9):1140-8. PMID: 27587581 
111. Comparing the Efficacy of Virtual and...

3. Ruiz JG, Mintzer MJ, Leipzig RM. The impact of E-learning in medical education. Acad Med. 2006;81(3):207-12. https:// doi.org/10.1097/00001888-200603000-00002

PMID: 16501260

4. Silmara RM,de Andrad CRF. Computer-assisted instruction in Speech-Language and Hearing Sciences: impact on motivation for learning about the Orofacialyofunctional System. CoDAS. 2016;28(3):269-77. http://dx.doi. org/10.1590/2317-1782/20162015143

5. Smith BR, Aguero-Rosenfeld M, Anastasi J, Baron B, Berg A, Bock J, et al. Educating Medical Students in Laboratory Medicine: A Proposed Curriculum. Am J Clin Pathol. 2010;133(4):53342. https://doi.org/10.1309/AJCPQCT94SFERLNI

6. Masic I, Pandza H, Toromanovic S, Masic F, Sivic S, Zunic L, et al. Information Technologies (ITs) in Medical Education. Acta Inform Med. 2011;19(3):161-7. https://doi. org/10.5455/aim.2011.19.161-167 PMID:23408471 PMCID:PMC3564180

7. Zehry K, Halder N, Theodosiou L. E-Learning in medical education in the United Kingdom. Procedia Soc Behav Sci. 2011;15:3163-7. https:// doi.org/10.1016/j.sbspro.2011.04.265

8. Gauchotte G, Ameisen D, Boutonnat J, Battistella M, Copie C, Garcia S, et al. The interuniversity learning website: a national university network for online teaching ofpathology. Ann Pathol. 2013;33(3):162-8. PMID:23790654

9. Alyusuf RH, Prasad K, Abdel Satir AM, Abalkhail AA, Arora RK. Development and validation of a tool to evaluate the quality of medical education websites inpathology. J Pathol Inform. 2013;4:29. https://doi.org/10.4103/21533539.120729 PMID:24392243

10. Degerfält J, Sjöstedt S, Fransson P, Kjellén E, Werner MU. E-learning programs in oncology: a nationwide experience from 2005 to 2014. BMC
Res Notes. 2017;10(1):39. https://doi.org/10.1186/ $\underline{\text { s13104-017-2372-8 PMID:28086959 }}$

11. Moazami F, Bahrampour E, Azar MR, Jahedi F, Moattari M. Comparing two methods of education (virtual versus traditional) on learning of Iranian dental students: a post-test only design study. BMC Med Educ. 2014;14:45. https://doi. org/10.1186/1472-6920-14-45 PMID:24597923 PMCID:PMC3975717

12. Sinn HP, Andrulis M, Mogler C, Schirmacher P. Virtual microscopy in pathology teaching and postgraduate training (continuing education). Pathologe. 2008;29(S2):255-8. https://doi. org/10.1007/s00292-008-1097-9 PMID:18843489

13. Al-Neklawy AF. Online Embryology teaching using learning management systems appears to be a successful additional learning tool among Egyptian medical students. Ann Anat. 2017;214:9-14. https://doi.org/10.1016/j. $\underline{\text { aanat.2017.07.001 }}$ PMID:28759739

14. Lichnovská R, Krajčí D, Erdösová B, Krajčí D. Our experience with e-learning method of teaching practical histology. Mefanet Journal. 2015;3(2):48-53. http://mj.mefanet.cz/mj$\underline{20150525}$

15. Makhdoom N, Khoshhal K, Algaidi S, Heissam K, ZolalyMA. Blended learning' as an effective teaching and learning strategy in clinical medicine: a comparative cross-sectional university-based study. J Taibah Univ Med Sci. 2013;8(1):12-7. https://doi.org/10.1016/j. jtumed.2013.01.002

16. Peroz I, Beuche A, Peroz N.Randomized controlled trial comparing lecture versus self studying by an online tool. Med Teach. 2009;31(6):508-12. https://doi.org/10.1080/01421 $\underline{590802203504}$

17. Khatony A,Dehghan Nayery N, Ahmadi F, Haghani H, Vehvilainen-Julkunen K. The effectiveness of web-based and face-to-face 
continuing education methods on nursorg/10.1186/1472-6920-9-41

PMID: 19591678 es' knowledge about AIDS: a comparative PMCID:PMC2717067

study. BMC Med Educ. 2009;9:41. https://doi.

Abdollahi A, Salarvand S, Saffar H. Comparing the Efficacy of Virtual and Conventional Methods in Teaching Practical Pathology to Medical Students. Iran J Pathol, 2018; 13(2): 108-112 